\title{
Severe Acute Dyspnoea of Extra-Thoracic Origin: Experience with Three Primary Thyroid Lymphomas (PTL)
}

\author{
Ana Adrienne Grüber ${ }^{\mathrm{a}}$, Sophie Zürcher ${ }^{\mathrm{b}}$, Daniel C. Betticher ${ }^{\mathrm{a}}$, Enzo Fontana ${ }^{\mathrm{b}}$
}

${ }^{a}$ Clinic of Medicine, Departments of Oncology and Endocrinology, HFR Fribourg-Hôpital Cantonal, Fribourg, Switzerland

${ }^{b}$ Clinic of Medicine, Department of Endocrinology, HFR Fribourg-Hôpital Cantonal, Fribourg, Switzerland

\begin{abstract}
Objectives: To recall the common clinical presenting features of and guide the diagnostic procedures of primary thyroid lymphomas (PTL).
\end{abstract}

Materials and methods: We report on three patients developing an acute dyspnoea and fast evolving neck mass in the thyroid caused by a PTL occurring in our regional hospital in Switzerland between 2009 and 2013.

Results: PTL causes a neck mass, dyspnoea and dysphonia and responds well to chemotherapy. Mortality is due to relapse or infectious complications.

Conclusion: Acute dyspnoea caused by thyroid disease is uncommon. Nevertheless, it is the main symptom in PTL due to rapid growth and compression of the airways. Chemotherapy should be started promptly.

Keywords: Thyroid, goiter, lymphoma, primary thyroid lymphoma

Received: $18 / 08 / 2014$

Accepted: $17 / 09 / 2014$

Published: $22 / 10 / 2014$

How to cite this article: Grüber A, Zürcher S, Betticher DC, Fontana E. Severe Acute Dyspnoea of Extra-Thoracic Origin: Experience with Three Primary Thyroid Lymphomas (PTL). EJCRIM 2014;1:doi: 10.12890/2014_000136

Conflicts of Interests: The authors declare that they have no conflicts of interest related to this research.

\section{Introduction}

Many diseases can cause dyspnoea, but an extra-thoracic origin is rarely the cause of rapid onset dyspnoea necessitating emergency treatment. We report here on three cases of severe acute dyspnoea caused by a very rare thyroid disease, primary thyroid lymphoma (PTL).

In our regional hospital, three patients presented with PTL between November 2009 and June 2013. The aim of this report is to share the common presenting features of these cases to improve diagnostic procedures for general practitioners and emergency doctors. 


\section{First case}

The first case was a 19-year-old man complaining of dysphonia, dysphagia, rapid onset of dyspnoea and a neck mass evolving over three weeks. On clinical examination, there was a firm goitre of the whole left lobe of the thyroid. The laboratory values were as follows: haemoglobin $144 \mathrm{~g} / \mathrm{l}$, leucocyte count $6.7 \mathrm{G} / \mathrm{l}$, platelet count $271 \mathrm{G} / \mathrm{l}$, thyroid-stimulating hormone (TSH) $6.4 \mathrm{mU} / \mathrm{l}$, T4 $13 \mathrm{pmol} / \mathrm{l}$ and C-reactive protein (CRP) $5 \mathrm{mg} / \mathrm{l}$. The thyroid ultrasound showed an enlarged left thyroid gland with an extreme hypo-echogenic pattern. The cervical CT scan (Fig. 1) revealed a large heterogeneous mass of the left lobe and isthmus of the thyroid gland resulting in a deviation and compression of the trachea and also of the left jugular vein. On cytological study, lymphomatous proliferation was suspected, and a thyroid biopsy confirmed a non-Hodgkin B-cell lymphoma of Burkitt type.

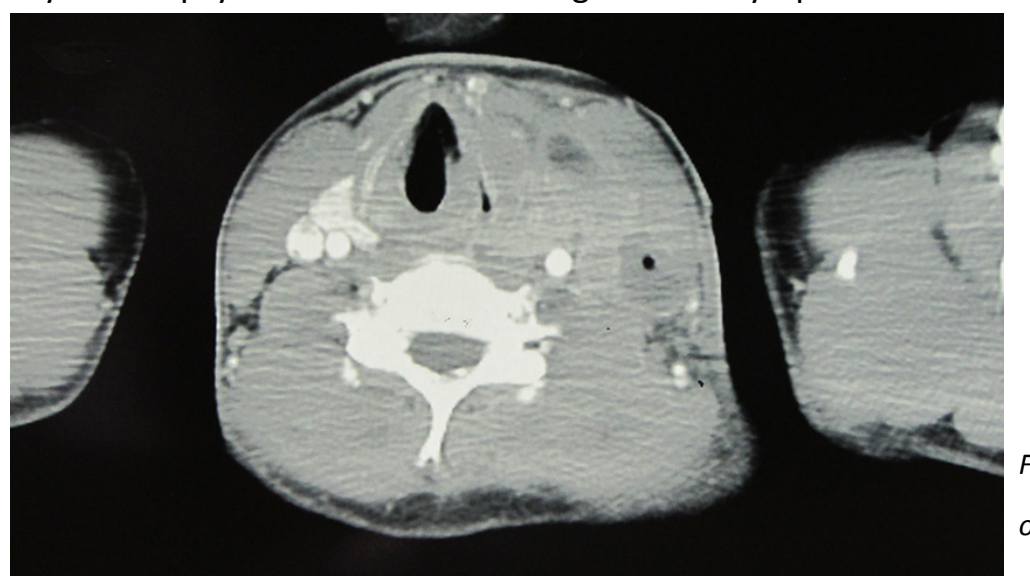

Figure 1: CT scan at diagnosis of a 19-year-old patient with PTL of Burkitt type

\section{Second case}

The second case was an 87-year-old woman presenting with acute onset of dyspnoea evolving over three weeks and a left latero-cervical mass. The laboratory values were as follows: haemoglobin $126 \mathrm{~g} / \mathrm{l}$, leucocyte count $5.4 \mathrm{G} / \mathrm{l}$, platelet count $205 \mathrm{G} / \mathrm{l}$, TSH $2.78 \mathrm{mU} / \mathrm{l}, \mathrm{T} 418 \mathrm{pmol} / \mathrm{l}, \mathrm{CRP}<5 \mathrm{mg} / \mathrm{l}$ and thyroglobulin $0.3 \mu \mathrm{g} / \mathrm{l}$ (normal value <55 $\mu \mathrm{g} / \mathrm{l}$ ). The ultrasound showed an enlarged hypo-echogenic thyroid gland. The CT scan (Fig. 2) confirmed an enlarged left thyroidal lobe deviating and compressing the trachea to the right. The biopsies were positive for a marginal zone lymphoma.

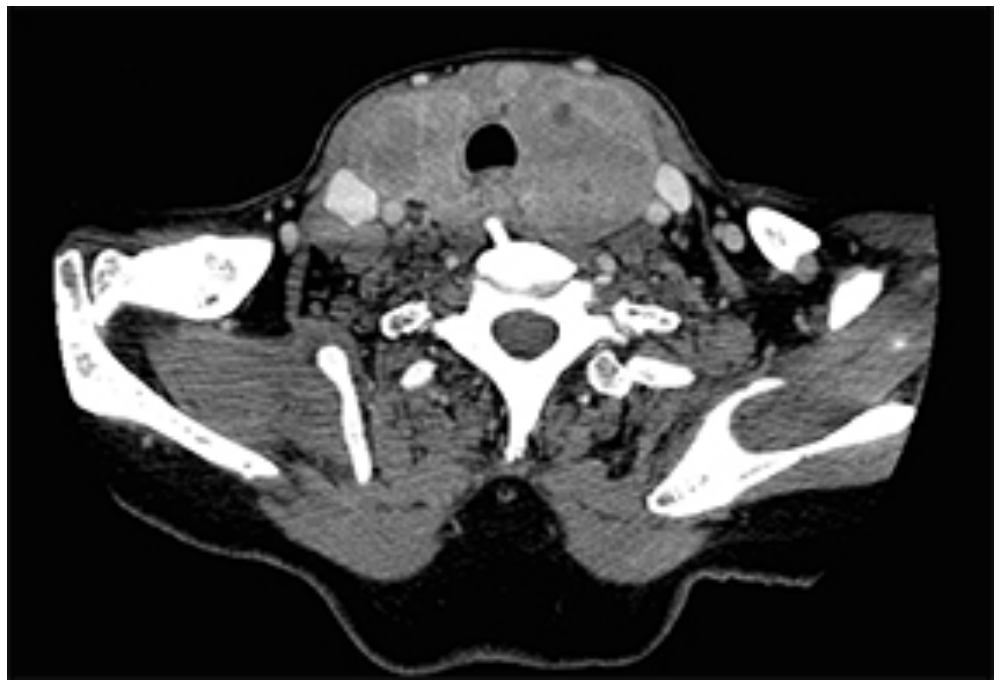

Figure 2: CT scan at diagnosis of 87-year-old woman with a primary thyroid marginal zone B-cell lymphoma 


\section{Third case}

The third case was a 68-year-old woman diagnosed at a routine check-up as having primary hypothyroidism 6 weeks before developing sudden dyspnoea. Her condition worsened very rapidly and she was referred to the emergency department of our hospital. On clinical examination, we described an enlarged and firm right thyroid lobe, hypo-echogenic on the neck ultrasound.

The laboratory values were as follows: haemoglobin $88 \mathrm{~g} / \mathrm{l}$, leucocyte count $10.4 \mathrm{G} / \mathrm{l}$; platelet count $415 \mathrm{G} / \mathrm{l}$, TSH 1.13 $\mathrm{mU} / \mathrm{l}(8.73 \mathrm{mU} / \mathrm{l}$ before receiving hormonal substitution), CRP $<5 \mathrm{mg} / \mathrm{l}$ and thyroglobulin $5.1 \mathrm{\mu g} / \mathrm{l}$. The CT scan (Fig. 3) showed an enlarged goitre compressing the trachea and causing deviation to the left. After respiratory stabilization, biopsies provided cytological confirmation of a diffuse large B-cell lymphoma.

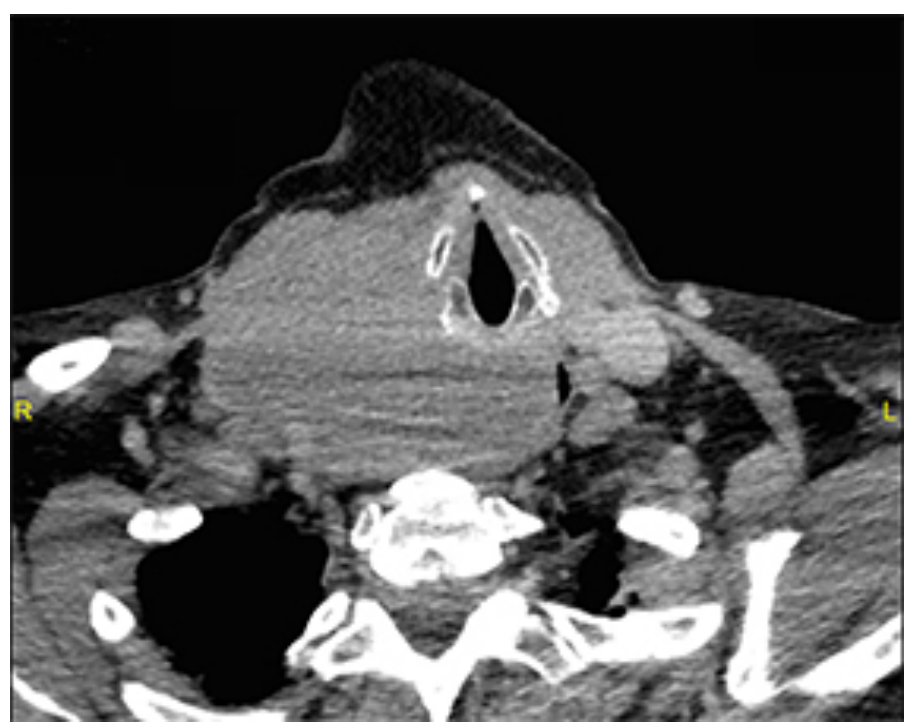

Figure 3: CT scan of a 68-year-old woman with diffuse large B-cell lymphoma of the thyroid

\section{Evolution}

The three patients received treatment according to their age as well as the stage and histological features of the lymphoma. The young male patient received two chemotherapy regimens of Prednison, CODOX-M cyclophosphamide, vincristine, doxorubicin, high-dose methotrexate) and IVAC (ifosfamide, etoposide, high-dose cytarabine) followed by cervical and mediastinal radiotherapy with a good initial response. All the symptoms disappeared within a week of starting the treatment. However, the disease progressed despite second-line therapy of EPOCH (prednisone, vincristine, etoposide, adriamycin and cyclophosphamide), and the patient died 4 months later.

The 87-year-old female received corticosteroids and radiotherapy to the neck, leading to partial remission. The symptoms disappeared quickly, but she relapsed 11 months later with multiple mediastinal and hilar nodes, which were then treated with rituximab for 3 months with partial remission. After local relapse 7 months later, she was further treated with six cycles of rituximab and bendamustine, with good clinical response lasting 2 months. She died of Enterobacter cloacae sepsis due to cholangitis, secondary to peritoneal carcinomatosis.

The 68-year-old female received corticosteroids, which greatly reduced the symptoms. She was then treated with R-CHOP with $50 \%$ dose reduction leading to a rapid reduction in thyroid volume. She died at Day 16 after the start of chemotherapy due to an acute respiratory distress syndrome with multiple organ failure in the context of nosocomial acquired pneumonia. 


\section{Discussion}

Extra-thoracic dyspnoea caused by thyroid enlargement is mainly found in a voluminous goitre developing over time and also sometimes after a sudden cystic haemorrhage with rapid increase in thyroid volume. PTL is an extra-thoracic condition of rapid onset that causes important painless dyspnoea. This disease remains a rare condition, with an incidence of less than two per million per year; it represents less than $2 \%$ of extranodal lymphomas [1] and accounts for less than $5 \%$ of all thyroid cancers. Derringer et al. described women as being at least twice as likely to be affected by the disease as men [2]. However, men are usually affected at a younger age, as we saw in our three patients.

Interestingly, two of the patients reported presented a normal thyroid function at the diagnosis of PTL. The main risk factor for developing the disease is Hashimoto thyroiditis, with a risk increase of $40 \%-80 \%$ compared to the general population, as seen in the Pedersen population-based study [1]. Our 68-year-old patient was diagnosed with Hashimoto thyroiditis some months previously and was treated with oral thyroxin.

The clinical presentation was similar for the three patients, with rapidly enlarging neck masses, and two of them presented with compressive symptoms including severe dyspnoea, dysphagia or voice hoarseness. Interestingly, the presence of these symptoms probably led to the diagnosis. None of them had B symptoms, as is usually the case in PTLs. On clinical examination, the main feature was a firm smooth mass.

PTL should be suspected when a large diffuse thyroid lesion has a hypo-echogenic pattern with an enhanced posterior echo at ultrasound. Some of them are pseudo-nodular with well determined borders, but most of the lymphomas are diffuse or of mixed type, which makes them harder to detect [3]. Two of the patients presented a very low thyroglobulin level not correlated with the thyroid volume but probably secondary to parenchymal destruction. The diagnosis was suggested by fine needle aspiration and confirmed by a core biopsy backed by immunohistochemical and immunophenotypization studies. The CT scan perfectly documented the effect of the mass on the trachea, showing compression and deviation as well as giving the staging of the disease (Figs. 1-3). Most of the patients presented at an early stage (IE or IIE), probably due to life-threatening symptoms occurring so soon.

Due to the low incidence of the disease, no randomized studies have evaluated a specific treatment, and therapy is given as for lymphomas of the same type in other localizations. In the case of an early staged indolent lymphoma, radiotherapy is offered in a curative attempt. In more advanced disease or more aggressive histologies, chemotherapy is the treatment of choice $[4,5]$. In fact, PTLs are very chemo-sensitive. Surgery has no role in the treatment, unless the mass compromises the upper airways. Poor prognostic factors include advanced age, aggressive histology (such as a diffuse large B-cell lymphoma), Stages III and IV, compressive symptoms, B symptoms, large mass and mediastinal invasion, as described by Derringer et al. [2] and Onal et al. [6].

\section{Conclusion}

Rapid onset of dyspnoea caused by thyroid disease is uncommon. Nevertheless, it is often the main symptom in PTL due to its rapid growth and compression of the upper respiratory airways. The diagnosis is suspected clinically and by ultrasound and is confirmed through biopsy. The treatment is similar to nodular lymphoma, based on chemotherapy and radiotherapy. This thyroid disease is a very rare condition; nonetheless, in the presence of dyspnoea due to a rapidly growing cervical mass, all general practitioners should be aware of this entity. 


\section{European Journal}

of Case Reports in

Internal Medicine

\section{Learning Points}

- PTL should be suspected in the case of rapid-onset dyspnoea or a fast-growing cervical mass.

- PTL is diagnosed by ultrasound and core biopsies.

- The treatment of PTL is based on chemotherapy and radiotherapy.

\section{References}

1. Pedersen RK, Pedersen NT. Primary non-Hodgkin lymphoma of the thyroid gland: a population based study, Histopathology 1996;28:25-32.

2. Derringer GA, Thompson LD, Frommelt RA, Bijwaard KE, Heffess CS, Abbondanzo SL. Malignant lymphoma of the thyroid gland: a clinicopathologic study of 108 cases, Am J Surg Pathol 2000;24:623-639.

3. Stein SA, Wartofsky L. Primary thyroid lymphoma: a clinical review, J Clin Endocrinol Metab 2013;98:3131-3138.

4. Ghielmini M, Vitolo U, Kimby E, Montoto S, Walewski J, Pfreundschuh M et al. ESMO Guidelines Consensus Conference on Malignant Lymphoma 2011. Part 1: diffuse large B-cell lymphoma (DLBCL), follicular lymphoma (FL), and chronic lymphocytic leukemia (CLL), Ann Oncol 2013;24:561-576.

5. Dreyling M, Thieblemont C, Gallamini A, Arcaini L, Campo E, Hermine O et al. ESMO Consensus Conferences: guidelines on malignant lymphoma part 2: marginal zone lymphoma, mantle cell lymphoma, peripheral T-cell lymphoma, Ann Oncol 2013;24:857-877.

6. Onal C, Li YX, Miller RC, Poortmans P, Constantinou N, Weber DC et al. Treatment results and prognostic factors in primary thyroid lymphoma patients: a rare cancer network study, Ann Oncol 2011;22:156-164.

\section{Acknowledgements}

We gratefully acknowledge Miss Rosalind Richards's critical revision and contribution to the article. 